\section{Pilares firmes contra a Arquitetura da Destruição}

\author{
Cláudia Affonso (iD) [0000-0002-0453-5542] \\ Colégio Pedro II, Rio de Janeiro, RJ, Brasil. \\ <professoraclaudiaaffonso@gmail.com>
}

PENNA, Fernando, QUEIROZ, Felipe, FRIGOTTO, Gaudêncio. (orgs). Educação democrática: antídoto ao Escola sem Partido. Rio de Janeiro: UERJ, LPP, 2018. 192 p.

Ao apresentar seu filme, em 1989, o sueco Peter Cohen nos convidava a um voo rasante sobre uma aldeia na qual, segundo ele, as pessoas ansiavam por um mundo mais puro e harmonioso, rejeitando as ameaças da decadência, o caos espiritual e intelectual que, segundo elas mesmas, conduziriam sua amada pátria à escuridão. Purificada do mal, protegida da degeneração moral e estética da cultura bolchevique e da degradação dos débeis, inúteis e parasitários, a nação renasceria bela, limpa e forte. Segundo Gerhard Wagner, médico-chefe do Bureau de Beleza no Trabalho, criado nos anos 1930 e retratado no filme, "se ao proletariado fosse mostrado como ele deveria se lavar e se elevar ao nível da burguesia, ele - o proletariado, entenderia que não havia porque lutar". Um verdadeiro despertar estético libertaria os trabalhadores de sua classe e a sociedade superaria o conflito de classes. Ditas e repetidas, orquestradas e estampadas, articuladas às condições de existência daquela Alemanha, estas verdades serviram de base para a Arquitetura da Destruição que se seguiu. Para o cineasta, a tarefa de evidenciar e denunciar esta 'arquitetura' fundamentaria o repúdio aos regimes antidemocráticos e seu banimento da História da humanidade.

No mesmo ano de 1989, do outro lado do Atlântico, a República parecia reinaugurarse. Na esteira dos avanços prometidos pela Constituição de 1988 e ansiados por boa parte dos brasileiros, respirava-se a noção de direito público universal, a defesa de princípios democráticos e a valorização das liberdades individuais e coletivas, abandonando os duros anos da ditadura civil militar das décadas anteriores. Se é verdade que não havia consenso em torno dos conteúdos da democracia e da cidadania, podemos afirmar com alguma convicção que cidadão - fosse o portador de direitos civis e sociais, fosse o de direitos do consumidor -, e cidadania foram os substantivos mais repetidos do período.Neste contexto, e não sem muita luta, a educação pública, laica, de qualidade e para todos parecia um projeto possível. A ressurgência de antigos movimentos sociais e o nascimento de novas formas de organização e mobilização, tanto de cunho popular quanto elitistas, dotavam a sociedade civil de feição estonteantemente dinâmica. Esperava-se a construção de uma democracia substantiva, independente do que isto quisesse dizer para os diversos grupos em disputa.

"A democracia em vertigem", documentário lançado por Petra Costa, em 2019, testemunha um dos pontos de chegada desta disputa. Capturadas no tempo presente, as imagens emolduradas pela narrativa da própria diretora conduzem o expectador a momentos de angústia e desolação: a democracia brasileira em frangalhos.

A frase: "A bandeira do Brasil jamais será vermelha", pronunciada no discurso de posse do atual Presidente do Brasil, Jair Bolsonaro, em $1^{\circ}$ de janeiro de 2019, talvez sirva de síntese metafórica daquilo que se instalou no Brasil nos anos recentes e que, como farsa - "um passado disfarçado voltando pela porta dos fundos" (Konder, 1995), repete a Arquitetura da Destruição. Baseado numa espécie de milenarismo míope, ou salvacionismo débil, o regime de ódio político e intolerância, parece sustentar-se em concepções éticas, morais e estéticas que em muito fazem lembrar o irracionalismo fascista. A repulsa à Educação Democrática, e de resto, às instituições democráticas como um todo é, certamente, uma das bases fortes desta construção. Não é sem razão que a disputa pela Escola se tornou o centro aglutinador do movimento/programa/ projeto/partido que, nos anos 2000, lançouse ao combate em defesa de um Deus opressor e da Teologia da Prosperidade, da família parental, da moral machista e das ideologias 
ultrareacionárias e ultraliberais, autonomeandose Escola Sem Partido (EsP) ${ }^{1}$.

Tudo isso para dizer: Educação Democrática: antidoto ao Escola Sem Partido, organizado por Fernando Penna, Felipe Queiroz e Gaudêncio Frigotto, é um livro imprescindível. E não apenas para quem se interessa por Educação. Lançado em 2018, reúne artigos de pesquisadores que àquela ocasião tinham assistido ao Golpe de 2016, mas não às eleições de outubro de 2018 e os primeiros meses do (des)governo Bolsonaro. Como o leitor logo perceberá, e talvez possa concordar, nem mesmo investigadores metódicos e criteriosos puderam antever o ritmo, a intensidade e a extensão da destruição que se seguiria. Aleatoriamente, mencionemos a Reforma Trabalhista, a subordinação do Ministério do Meio Ambiente ao Ministério da Fazenda, a liberação de um sem número de agrotóxicos, a extinção do Programa Mais Médicos e a 'expulsão' dos médicos cubanos em atividade no Brasil, o Decreto das Armas, os gigantescos cortes no financiamento da Educação Pública, a nomeação de Sérgio Moro Ministro da Justiça e da Segurança Pública e a avalanche de denúncias contra ele e, agora mesmo, a Reforma da Previdência. Ou, algum detalhe mais sutil, mas igualmente significativo, como a estratégia negacionista em relação ao Golpe Militar de 1964 e à Ditadura Militar que tem suscitado mecanismos de autocensura entre renomados autores e professores de História e Sociologia; ou a defesa que fez o Presidente da República ao afirmar que quer um futuro ministro do STF "terrivelmente" cristão, leia-se evangélico.

Se o livro 'não viu tudo isto' e, portanto, não traz a análise desta dramática conjuntura e suas implicações na fórmula do "Antídoto ao Escola sem Partido", o que faz o livro? Aqui situa-se o ponto de inflexão mais importante que podemos tomar neste momento, segundo me parece. A obra faz 'formação de base', fundamenta pilares teóricos e, por que não dizer, ético-políticos para o enfrentamento que está em questão. Numa frase, tomada de empréstimo à Marise Ramos que assina a Introdução e inspirada na obra de Ellen Wood, Democracia contra capitalismo 2003, oferece muitas pistas para os que pensam que a democracia "em sua plenitude é incompatível com o capitalismo e odiada pela oligarquia dominante, não se pode lográ-la. Isto porém, não elide - ao contrário exige - a luta por sua conquista." (p. 8).

Tomada como tarefa coletiva, a construção de pilares para o enfrentamento da desdemocratização do Brasil se faz de forma generosa e abundante ao longo dos textos. Em seu conjunto, o livro pode ser lido como resultado de três movimentos articulados: a delimitação criteriosa do 'fenômeno' Escola sem Partido, identificando e analisando suas bases materiais, institucionais e sua estratégia discursiva; a busca metódica das determinações históricas que conduziram à regressão das relações sociais capitalistas com a negação de seus postulados de integração dos indivíduos na diversidade social e do papel da escola no processo de socialização dos indivíduos nos valores do convívio coletivo e, a proposição de táticas de enfrentamento desta regressão, notadamente, o fortalecimento do Movimento Escola Democrática com perspectiva de gênero emancipatória. O 'antídoto' está, para os autores, na luta por democracia e escola democrática.

A análise do 'fenômeno' EsP, para o qual “O que verdadeiramente está acontecendo é que o conceito de 'gênero' está sendo utilizado para promover uma revolução sexual de orientação neo-marxista com o objetivo de extinguir da textura social a instituição familiar" (p.101), encontra-se em praticamente todos os textos. A diferença de ênfase talvez particularize as contribuições. Assim, os aspectos institucionais do EsP podem ser lidos em "Liberdade para a democracia: considerações sobre a institucionalidade da Escola sem Partido", de Felipe Queiroz e Rafael Oliveira e "Direito à educação democrática: conquistas e ameaças", de Russel da Rosa. Os aspectos discursivos são perscrutados em "Como o discurso da 'ideologia de gênero' ameaça o caráter democrático e plural da escola", de Giovanna Marafon e Marina Souza; "O Movimento Escola sem Partido e a reação conservadora contra a discussão de gênero na escola", de Fernando de Moura; "É que Narciso acha feio o que não é espelho: o ensinar e o aprender pela ótica do EsP", de Carina Costa e Luciana Velloso e "A EsP na desdemocratização brasileira", de Diogo Salles e Renata Silva. A análise do problema do ponto de vista das disputas históricas em torno da Escola, 
daquilo que Carlos Jamil Cury nomeou como "Educação e Contradição" (1995), encontrase em "A disputa por educação democrática em sociedade antidemocrática", de Gaudêncio Frigotto e "Instrutio ou Educatio", de Zacarias Gama. O centro da formulação tática encontrase, segundo minha leitura, em "Construindo estratégias para uma luta pela educação democrática em tempos de retrocesso", de Fernando Penna, mas também, e fortemente, no já citado texto de Giovana Marafon e Marina Souza.

Aos que sentem o ânimo combalido diante de tamanha avalanche, sirvo-me de duas imagens para concluir esta recomendação de leitura. A primeira está no Prólogo do também imperdível A era do cometa, do historiador alemão Daniel Schönpflug (2018). Apropriando-se da tela "O cometa de Paris" (1918), de Paul Klee, ele descreve um contexto que "mirava exatamente esse limiar entre o passado e o futuro, entre a realidade e as projeções" (Schönpflug, 2018, p. 13). Tratava-se do ano de 1918, final da Primeira Grande Guerra Mundial e ano um da Revolução Russa. Usado como metáfora para definir um sinal do imprevisível, um arauto de grandes acontecimentos, de transformações profundas e, até mesmo, de catástrofes, o cometa representa o alvorecer de novas e impensadas possibilidades no horizonte, e futuros desconhecidos. Lembremo-nos que, percebidos ou não, cometas seguem cruzando o céu ${ }^{2}$.

A segunda, não menos importante, e que devemos a Gramsci, reafirmar o pessimismo da inteligência, otimismo da vontade. As diversas sínteses, organizadas em artigos independentes, nos permitem avançar rapidamente na fixação de pilares firmes para a luta por democracia radical e plural.

Eis o antídoto. Eis a tarefa.

Boa leitura!

\section{Notas}

${ }^{1} \mathrm{O}$ esforço analítico empreendido por FRIGOTTO, Gaudêncio (Org). Escola "sem" partido: esfinge que ameaça a educação e a sociedade brasileira. Rio de Janeiro: UERJ, LPP, 2017 merece ser considerado pelos que desejam compreender melhor o fenômeno.

${ }^{2}$ CÁSSIO, Fernando (org.). Educação contra a barbárie: por escolas democráticas e pela liberdade de ensinar. São Paulo: Boitempo, 2019. é mais uma luz no céu escuro.

\section{Referências}

CURY, Carlos Jamil. Educação e contradição: elementos metodológicos para uma teoria crítica do fenômeno educativo. SP, Cortez, 1995. $7^{\text {a }}$ ed

KONDER, Leandro. O novo e o velho. O Globo. 27/05/1995

SCHÖNPFLUG, Daniel. A era do cometa: o fim da primeira guerra e o limiar de um novo mundo. São Paulo: Todavia, 2018, p.13 